\title{
Complete recovery of a masked visual target
}

\author{
ALFRED B. KRISTOFFERSON, JOHN GALLOWAY, and ROBERT G. HANSON \\ McMaster University, Hamilton, Ontario L8S 4K1, Canada
}

\begin{abstract}
The experiment by Dember and Purcell (1967) was repeated and extended using four subjects over many sessions. When the time interval between target onset and the onset of the second mask was $116 \mathrm{msec}$, and that between the first mask and the second mask was $35 \mathrm{msec}$, complete recovery of the masked target was obtained for all subjects. Lengthening or shortening the 35 -msec interval produced less than complete recovery.
\end{abstract}

A brief visual target stimulus ( $\mathrm{T}$ ) that has been masked by a second stimulus (M1) presented a short time later may be perceived (recovered) if a third stimulus (M2) is presented following M1. This phenomenon was first described by Robinson (1966), who suggested that $\mathrm{M} 2$ disinhibits $\mathrm{T}$ by masking $\mathrm{M} 1$. The theoretical significance of such target recovery resides in the implication that masking does not always erase the information imparted by $\mathrm{T}$.

Using stimulus conditions similar to Robinson's (1966), Schurman and Eriksen (1969) failed to obtain recovery for two subjects. Changing the conditions, they found the opposite of recovery for three subjects: $\mathrm{M} 2$, while not masking $\mathrm{T}$ by itself, summated with $\mathrm{M} 1$ to cause more masking than $\mathrm{M} 1$ produced alone. Dember and Purcell (1967) also questioned Robinson's conclusion, pointing out that certain conditions that are crucial to those conclusions were not included in his experimental design. They presented data from two experiments that used stimuli differing from Robinson's, but which included the necessary experimental conditions. Their target was one of two black-on-white letters, and forced-choice recognition was required. The first mask was a black disk (D) covering the area previously occupied by $\mathrm{T}$. The second mask was a black ring (R) with an inner diameter equal to the diameter of D. Four experimental conditions were included, randomized from trial to trial: (1) $\mathrm{T}$ alone, (2) $\mathrm{T}+\mathrm{D}$, (3) $T+R$, and (4) $T+D+R$. The stimulus onset asynchrony (SOA) for $T$ and $D\left(t_{1}\right)$ was $51 \mathrm{msec}$, and the SOA for $D$ and $R\left(t_{2}\right)$ was $35 \mathrm{msec}$ in their first experiment. In a second experiment, the only change was to increase $t_{1}$ to $81 \mathrm{msec}$. No obvious recovery effect was obtained for the 25 subjects, who were run individually in a single session in the first experiment. The second experiment, which studied 25 new subjects each in a single session, did yield evidence of recovery. The obtained proportion of correct responses was significantly higher for the condition $T+D+R$ than for the condition $T+D$, but the magnitude of the effect was quite small.

Dember, Schwartz, and Kocak (1978) have recently

The data reported in this paper are part of two senior honors theses accepted by McMaster University, one by R. G. Hanson in 1968, and the other by J. Galloway in 1969. shown substantial recovery of a masked visual target. The four experimental conditions described above were used again, but the stimulus conditions were markedly different from those used by Dember and Purcell (1967). As before, recognition of a single target letter was measured, but now M1 was a field of visual noise and $\mathrm{M} 2$ was a homogeneous white field having a diameter twice that of M1. Stimulus field luminances were unequal and the temporal parameters of stimulation were very different, $t_{1}$ and $t_{2}$ being 17 and $30 \mathrm{msec}$, respectively, and the durations of $\mathrm{T}, \mathrm{M} 1$, and $\mathrm{M} 2$ being 10,20 , and $30 \mathrm{msec}$. A large masking effect was obtained: All responses were correct when only $\mathrm{T}$ was presented, but only $43 \%$ were correct when M1 followed $\mathrm{T}$. The condition $\mathrm{T}+\mathrm{M} 1+\mathrm{M} 2$ gave $84 \%$ correct, while the result for $\mathrm{T}+\mathrm{M} 2$ was $99 \%$. Thus, target recovery due to M2 was large and, while it was considerably short of being complete, it was nearly complete for 7 of 16 subjects.

Our present purpose is primarily to report our replications of the Dember and Purcell (1967) experiment. We have found that target recovery is not only substantial under their conditions, but it is complete, at least for some subjects. The one difference between their work and ours is that we studied a few subjects each for many sessions, whereas they studied many subjects each for a single session.

\section{METHOD}

Four, young, adult, male subjects were used and paid for their services and no subjects were discarded. All stimulus dimensions, luminances, and durations were as described by Dember and Purcell (1967), as were the tachistoscope, mode of viewing (monocular), fixation field, preliminary dark adaptation, and structure of a single experimental session (50 trials of each of four conditions, randomly mixed).

A target, either the letter $\mathrm{D}$ or the letter $\mathrm{O}$, was presented on every trial, and the subject was asked to identify it. All stimuli were black on white. M1 was a black disk and M2 was a ring ( $D$ and $R$, as described above). The durations of $T, D$, and $R$ were 1,5 , and $50 \mathrm{msec}$, respectively. The SOA between $T$ and $D$ is $t_{1}$ and that between $D$ and $R$ is $t_{2}$; their values are given in Table 1. A trial was one of the four conditions $T$, $\mathrm{T}+\mathrm{D}, \mathrm{T}+\mathrm{R}$, or $\mathrm{T}+\mathrm{D}+\mathrm{R}$.

All four subjects began with 10 consecutive sessions under the exact conditions of Dember and Purcell's (1967) Experiment $2\left(t_{1}=81 \mathrm{msec}\right.$ and $\left.t_{2}=35 \mathrm{msec}\right)$. For two subjects, $t_{1}$ was then changed to $61 \mathrm{msec}$ and five more sessions were run. 
For the other two subjects, $t_{2}$ was changed as indicated in Table 1, with five sessions at each value before changing to the next value.

\section{RESULTS}

The top four rows of Table 1 contain the results for the replication of Dember and Purcell's (1967) Experiment 2. All four subjects show a substantial masking effect by $\mathrm{D}$, the mean proportion correct, corrected for chance, being .58 for $\mathrm{T}$ alone and .24 for $\mathrm{T}+\mathrm{D}$. At this SOA of $116 \mathrm{msec}, \mathrm{R}$ exerts no masking on $T$, but $R$ does bring $T+D$ back up to the level of $T$ alone, that is, target recovery is complete. All subjects show the same pattern.

When $t_{1}$ is reduced to $61 \mathrm{msec}$ (bottom two rows), $\mathrm{R}$ has a small masking effect on $\mathrm{T}$, the masking effect of $D$ is slightly greater, and the recovery effect is probably smaller. This pattern is similar to Dember and Purcell's (1967) Experiment 1, except that here the recovery effect is significant. In their Experiment 1 , $t_{1}$ was $51 \mathrm{msec}$, and no recovery was observed.

Bringing the ring closer to the disk by reducing $t_{2}$ to 20 msec causes some masking of $T$ by $R$ and diminishes the recovery effect. Increasing $t_{2}$ to values greater than $35 \mathrm{msec}$ also diminishes the amount of recovery. Maximum target recovery occurs here when the ring is presented $35 \mathrm{msec}$ following the onset of the disk; Dember and Purcell (1967) made a fortunate choice for $t_{2}$.

\section{DISCUSSION}

Under certain conditions, a second mask presented later than a first mask results in recovery of the target. We have found recovery to be complete under the conditions of the original Dember and Purcell (1967) experiments when temporal parameters are optimal, and we cannot account for the greater strength of the effect in our experiments compared to theirs. It is probably not due to the greater practice that our subjects went through, because the recovery effect did not change systematically during the 10 sessions of the main experiment. Dember et al. (1978) found almost complete recovery for half their subjects, but Dember and Purcell (1967) did not give the results for individual subjects.

Evaluating the magnitude of the various effects in experiments like these can be accomplished only crudely in the absence of a detailed model. Whether the size of an obtained effect is called "moderate" or "substantial" or even "complete" may depend upon the model. One model that can be considered here is a simple two-state recognition model in which the various stimuli are assumed to have independent, probabilistic effects. The internal outcome on each trial is either a recognition state $Z$ or a nonrecognition state $\bar{Z}$. A correct response always occurs when the outcome is $Z$, but it occurs only by chance given $\bar{Z}$. Presentation of $T$ alone yields $Z$ with probability $P_{D}$. If $D$ is also presented, its masking effect is expressed by $\mathbf{P}_{\mathbf{M}}$, which is the probability that it will convert a $Z$ state produced by $T$ into a $\bar{Z}$ state. Similarly, $R$ converts $Z$ states into $\bar{Z}$ states with probability $P_{R}$, regardless of whether $Z$ is one that has survived $D$ or has occurred in the absence of $D$. Target recovery is represented by $P_{R M}$, a second effect of $R$, which is the probability that $R$ will reconvert $\bar{Z}$ states created by $M$ into $Z$ states (and only those $\overline{\mathrm{Z}}$ states).

The four parameters of the model (the probability of recogni-
Table 1

Proportion of Responses Correct, Uncorrected for Chance, for Each Subject Under Each Experimental Condition

\begin{tabular}{|c|c|c|c|c|c|c|c|}
\hline \multirow[b]{2}{*}{$t_{1}$} & \multirow[b]{2}{*}{$t_{2}$} & \multirow{2}{*}{$\begin{array}{l}\text { Trials per } \\
\text { Condition }\end{array}$} & \multirow[b]{2}{*}{ Subject } & \multicolumn{4}{|c|}{$\begin{array}{c}\text { Proportion of Correct } \\
\text { Responses }\end{array}$} \\
\hline & & & & $T$ & $T+D$ & $\mathrm{~T}+\mathrm{D}+\mathrm{R}$ & $T+R$ \\
\hline \multirow[t]{2}{*}{81} & 35 & 500 & $\begin{array}{l}\text { R.T. } \\
\text { K.W. } \\
\text { E.B. } \\
\text { S.C. }\end{array}$ & $\begin{array}{l}.86 \\
.73 \\
.78 \\
.80\end{array}$ & $\begin{array}{l}.73 \\
.56 \\
.58 \\
.60\end{array}$ & $\begin{array}{l}.84 \\
.71 \\
.79 \\
.77\end{array}$ & $\begin{array}{l}.88 \\
.71 \\
.79 \\
.79\end{array}$ \\
\hline & & & Mean & .79 & .62 & .78 & .79 \\
\hline 81 & 20 & 250 & $\begin{array}{l}\text { E.B. } \\
\text { S.C. }\end{array}$ & $\begin{array}{l}.82 \\
.80\end{array}$ & $\begin{array}{l}.62 \\
.58\end{array}$ & $\begin{array}{l}.76 \\
.66\end{array}$ & $\begin{array}{l}.74 \\
.72\end{array}$ \\
\hline 81 & 50 & 250 & $\begin{array}{l}\text { E.B. } \\
\text { S.C. }\end{array}$ & $\begin{array}{l}.76 \\
.78\end{array}$ & $\begin{array}{l}.63 \\
.61\end{array}$ & $\begin{array}{l}.69 \\
.67\end{array}$ & $\begin{array}{l}.76 \\
.75\end{array}$ \\
\hline 81 & 80 & 250 & $\begin{array}{l}\text { E.B. } \\
\text { S.C. }\end{array}$ & $\begin{array}{l}.77 \\
.74\end{array}$ & $\begin{array}{l}.57 \\
.60\end{array}$ & $\begin{array}{l}.68 \\
.61\end{array}$ & $\begin{array}{l}.73 \\
.71\end{array}$ \\
\hline 61 & 35 & 250 & $\begin{array}{l}\text { R.T. } \\
\text { K.W. }\end{array}$ & $\begin{array}{l}.84 \\
.76\end{array}$ & $\begin{array}{l}.60 \\
.54\end{array}$ & $\begin{array}{l}.71 \\
.73\end{array}$ & $\begin{array}{l}.79 \\
.69\end{array}$ \\
\hline
\end{tabular}

zing $T$ presented alone, the masking probabilities of $D$ and of $R$, and the recovery probability) can be estimated from the four experimentally obtained response probabilities. Doing so alters none of the conclusions stated above, but the model does illuminate certain points that are worth mentioning. When the probability of target recovery is unity and the masking effect of the ring on the target is zero, then the obtained proportion of correct responses will be the same for condition $T+D+R$ as for condition $T$ (for any value of $P_{D}$ ). But, if the masking effect of $R$ upon $T$ is greater than zero, then the proportion correct for $T+D+R$ will be less than that for $T$ alone, even when the recovery probability is unity (but only when $\mathbf{P}_{\mathbf{M}}$ is less than unity). The main point is that recovery may be complete in this model even though $T+D+R$ does not bring $P(c)$ all the way back up to the amount found for $T$ alone from the lower level observed for $T+D$. The amount of the discrepancy depends upon $\mathbf{P}_{\mathbf{M}}$ and $\mathbf{P}_{\mathbf{R}}$.

Dember et al. (1978) have stated that "one reasonable implication of recovery is that masking does not entirely remove the representation of the target from the visual system." Do they imply thereby that, when the target is followed by both masks, it is first masked by the first mask and later recovered by the second mask? That is a reasonable implication, but it seems to us quite possible that masking is erasure, and that the second mask has the effect of preventing erasure of the target by the first mask. The significance of the recovery phenomenon would then be that erasure, when it occurs, does not occur until much later than might be expected on the basis of single-mask experiments. Perception of a target may have a latency even longer than the quite long time we have come to suspect.

\section{REFERENCES}

Dember, W. N., \& Purcell, D. G. Recovery of masked visual targets by inhibition of the masking stimulus. Science, 1967, 157, 1335-1336.

Dember, W. N., Schwartz, M., \& Kocak, M. Substantial recovery of a masked visual target and its theoretical interpretation. Bulletin of the Psychonomic Society, 1978, 11, 285-287.

Robinson, D. N. Disinhibition of visually masked stimuli. Science, 1966, 154, 157-158.

Schurman, D. L., \& Eriksen, C. W. Summation and interaction of successive masking stimuli in visual perception. American Journal of Psychology, 1969, 82, 320-332.

(Received for publication September 12, 1978.) 